\title{
THE CONSEQUENCES OF CHILD SOLDIERING
}

\author{
Christopher Blattman and Jeannie Annan*
}

\begin{abstract}
Little is known about the impacts of military service on human capital and labor market outcomes due to an absence of data as well as sample selection: recruits are self-selected, screened, and selectively survive. We examine the case of Uganda, where rebel recruitment methods provide exogenous variation in conscription. Economic and educational impacts are widespread and persistent: schooling falls by nearly a year, skilled employment halves, and earnings drop by a third. Military service seems to be a poor substitute for schooling. Psychological distress is evident among those exposed to severe war violence and is not limited to excombatants.
\end{abstract}

\section{Introduction}

$\mathrm{T}$ HIS paper assesses the impact of combat on the human capital of Ugandan youth, the consequences for lifetime labor market performance, and lessons for the economic recovery of civil war-torn countries. Civil conflict has afflicted a third of all nations and two-thirds of Africa since 1991 (Marshall \& Gurr, 2005). The recovery of children and young adults is a critical concern in these postwar economies; lost education can take years to regain, and physical and psychological trauma may be long-lasting. Some of these conflicts involve up to a third of male youth in active combat, many of whom are children under age 18 . With so many millions of young ex-combatants, injuries to human capital could hinder a nation's productivity and growth for decades. Moreover, any impact of military service on inequality, aggression, and alienation could threaten a nation's long-term stability.

The effects of combat are uncertain. The dominant view holds that these youth are traumatized, violent, social pariahs. Speaking at a 2007 U.N. conference, the French foreign minister warned that young ex-combatants are "a time bomb that threatens stability and growth, ... lost for peace and lost for the development of their countries" (BBC, 2007). Former child soldiers in particular are "damaged, uneducated pariahs," says a New York Times editorial ("Armies of Children," 2006). A growing body of ethnographic evidence portrays another view, however, finding

Received for publication May 1, 2008. Revision accepted for publication March 6, 2009.

* Blattman: Yale University, Political Science and Economics; Annan: Yale University, School of Medicine and CIRA.

Macartan Humphreys, Edward Miguel, Chalmer Thompson, and Jeremy Weinstein deserve special thanks for their input and guidance. For comments, we also thank David Albouy, Tim Allen, Matias Cattaneo, Bryan Graham, Chang-Tai Hsieh, Guido Imbens, Pamela Jakiela, Seema Jayachandran, Stathis Kalyvas, Kory Kroft, David Lee, David Leonard, David Lynch, Lauren Morris-MacLean, Devin Pope, Gerard Roland, Amos Sawyer, Thomas Sexton, Harvey Weinstein, our anonymous referees, and numerous seminar participants. For data collection, we thank Roger Horton, Okot Godfrey, and our field research assistants. Robert Blair provided excellent research assistance. Logistical support was supplied by AVSI Uganda and UNICEF Uganda. Military escorts were provided by the Uganda People's Defense Force. Financial support was primarily received from UNICEF, the John D. and Catherine T. MacArthur Foundation, the U.S. Institute of Peace, and the Harry Frank Guggenheim Foundation. that resilience rather than disabling psychological trauma is the norm (Shepler, 2005; Boothby, Crawford, \& Halperin, 2006; Wessells, 2006).

Virtually no representative data or well-identified causal estimates exist to judge either set of claims (Blattman \& Miguel, 2010). A small literature has found large and persistent earnings and mortality gaps between veterans and nonveterans in the United States and Europe (Hearst, Newman, \& Hulley, 1986; Angrist, 1990, 1998; Angrist \& Krueger, 1994; Imbens \& van der Klaauw, 1995). For instance, Angrist (1990) finds that white American males conscripted into the Vietnam War saw a 15\% reduction in their longterm earnings due to work experience lost, while Costa and Kahn (2010) use data on U.S. Civil War veterans to link wartime stress to higher mortality later in life. The impacts of combat, however, are not uniformly bad; both U.S. studies, for instance, find that military service increased the human capital and lifetime earnings of black Americanssad evidence of their otherwise poor alternatives.

Unfortunately, these findings do not generalize easily to the developing countries where most civil wars rage. They also draw on data sets with a limited range of outcomes, and so the full nature of the impact (and the causal channel) is hard to see. The sole survey-based study of the impact of civil war combat comes from a pioneering survey of Sierra Leonean ex-combatants by Humphreys and Weinstein (2004, 2007). They find that increased exposure to violence is associated with lower community acceptance but not with employability. Without a noncombatant comparison group, however, our understanding of the impact of military service remains incomplete.

One reason we know so little about these impacts is the paucity of data in war zones. To overcome this problem, we conducted a survey during the war in northern Uganda, where for 20 years, an unpopular rebel group has forcibly recruited tens of thousands of youth.

A second challenge in identifying the causal effects of military service is selection: ex-fighters are usually a select group, including those who chose to join and those screened by the armed force. The ideal research design would be one where rebel participation was randomly or exogenously assigned. We argue that forced recruitment in Uganda resembles just such a terrible case. Under the assumption that abduction is conditionally unconfounded, causal impacts can be estimated using noncombatants of the same year and place of birth as counterfactuals. Naturally, unobserved sources of selection and survival could bias the results. Hence we explicitly model the sensitivity of the treatment effects to unobserved selection to show that moderate to large amounts of selective abduction and attrition cannot account for the causal effects or change our general conclusions. 
The results suggest that the largest and most pervasive impact of abduction is on education and earnings, largely due to time away from civilian schooling and work experience. This educational deficit impedes labor market success: while abducted youth are just as likely to be employed, they are half as likely to be engaged in skilled work and earn wages that are lower by a third.

The data also support a growing body of ethnographic evidence that finds ex-soldiers to be socially and psychologically resilient. Community acceptance of former abductees is high, and they report similar levels of social support as do nonabductees. Abductees also exhibit little difference in aggression. Finally, we highlight evidence that formerly abducted youth do report $15 \%$ more symptoms of emotional distress, in large part because of exposure to more extreme violence (Annan \& Blattman, 2009). Considering the high incidence of violence received and perpetrated, this result speaks to a remarkable resilience among youth, even among those youth reporting the highest levels of distress, a conclusion bolstered by in-depth interview evidence (Annan, Brier, \& Aryemo, 2008).

These results challenge the conventional assumptions about ex-combatants. Unfortunately our counterfactualnonabducted youth in the war zone-does not help to identify the impact of war on noncombatants. Rather, our approach assesses the added impact of military service on youth already in a war zone. This incremental effect is important in order to address postwar gaps in reintegration, especially when so many policymakers and aid agencies appear to be ignoring the largest gaps. We conclude with policy lessons for ex-combatant reintegration and postconflict recovery.

\section{Background}

\section{A. War and Abduction in Northern Uganda}

Historically Uganda's economic power rested in the south, while political and military power came from the north (Omara-Otunnu, 1994). In 1986, however, southern rebels overthrew a government and army dominated by a northern ethnic group, the Acholi. Several Acholi guerrilla forces resisted the takeover, but settled for peace or were defeated by 1988. A handful of these fighters refused to settle, however, and gathered under a spiritual leader named Joseph Kony to form the Lord's Resistance Army (LRA; Doom \& Vlassenroot, 1999; Allen, 2005). Like many other armed group leaders in Africa, Kony is widely believed to possess spiritual powers. He claims to seek a spiritual cleansing of Uganda and theocratic rule.

The decision to continue fighting was an unpopular one, however, and the LRA received little public support. With few recruits and no material resources, the LRA immediately took to looting homes and abducting youth to maintain supplies and force. The Acholi populace, after three years of such abductions and looting, began to join a government- sponsored defense militia in 1990. To punish this betrayal and dissuade further collaboration, in 1991 Kony ordered the widespread killing and mutilation of Acholi civilians, further alienating the population (Behrend, 1999; Branch, 2005).

LRA activity was initially low, but in 1994 and 1995, in response to Uganda's support for Sudanese rebels, the government of Sudan began supplying Kony with weapons and territory on which to build bases. Sudan's support invigorated the LRA, and rebel attacks and abductions escalated dramatically after 1996.

Abduction was on a large scale and seemingly indiscriminate; 60,000 to 80,000 youth are estimated to have been abducted (Annan, Blattman, \& Horton, 2006; Pham, Vinck, $\&$ Stover, 2007), and more than a quarter of males currently aged 14 to 30 in our study region were abducted for at least two weeks (table 1). Most were abducted after 1996 and from one of the Acholi districts of Gulu, Kitgum, or Pader (figure 1).

Youth were typically taken by roving groups of ten to twenty rebels during night raids on rural homes. Adolescent males appear to have been the most pliable, reliable, and effective forced recruits, and so were disproportionately targeted by the LRA (Beber \& Blattman, 2008). Youth under age 11 and over 24 tended to be avoided, as seen in figure 2 , and had a high probability of immediate release. Lengths of abduction ranged from 1 day to 10 years, averaging 8.9 months in our sample (table 1). Youth who failed to escape were trained as fighters and, after a few months, received a gun. Two-thirds of abductees were forced to perpetrate a crime or violence. A third eventually became fighters, and a fifth were forced to murder soldiers, civilians, or even family members in order to bind them to the group, reduce their fear of killing, and discourage disobedience.

Eighty-four percent of abductees eventually escaped, usually in an unsupervised moment such as the heat of battle. The remainder perished, as no more than 1,000 abducted youth (about $1 \%$ of all abductees) are thought to remain with the LRA at this time. An amnesty has been granted to all "returnees" and community acceptance rates are high; fewer than $2 \%$ report insults or fear from their community and family.

\section{B. Current Practice and Evidence}

The focus on trauma in the wake of war and disaster is pervasive, and youth postconflict programs concentrate heavily on psychosocial care (Cohn \& Goodwin-Gill, 1994; Machel, 1996; ILO, 2003; CSUCS, 2005; Wessells, 2006). In Uganda, foreign aid has concentrated on psychosocial programs for former abductees, a focus driven by abundant anecdotal evidence of social rejection and trauma. For example, one youth we interviewed is haunted by being forced to kill his brother: "I started dreaming of him a week after the incident, and at times I would see him during the day. How I beat him would all re-surface." Frequently reliving such events through nightmares or flashbacks is a 


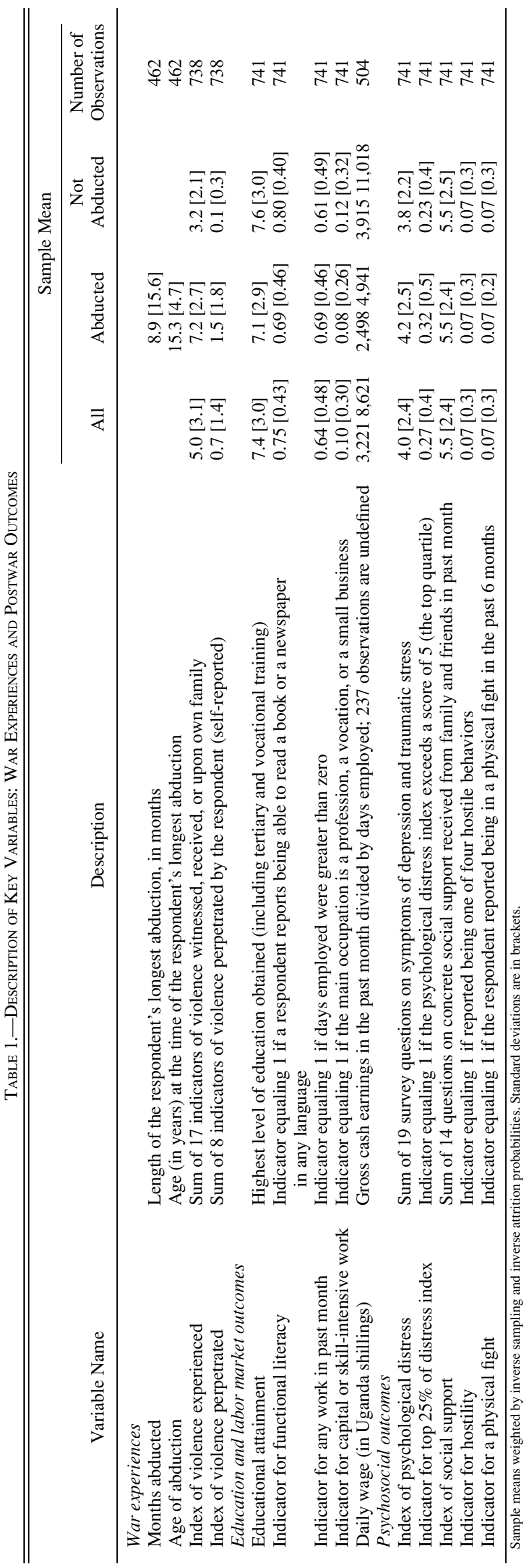

common symptom following traumatic events, and nightmares are one of the most commonly reported symptoms of distress in the sample (Annan \& Blattman, 2009).

Some psychological studies emphasize high levels of traumatic stress among child soldiers. One Ugandan study compared abducted to nonabducted youth in the war zone and concluded that abducted youth were more anxious and depressed, more hostile, less prosocially active, and less confident (MacMullin \& Loughry, 2002). A second study identified clinical posttraumatic stress in $97 \%$ of abductees (Derluyn et al., 2004). Both studies, however, used nonrandom convenience samples and did not discuss potential selection effects. The validity of their conclusions is thus questionable.

In contrast, other literature on child and refugee mental health emphasizes the resiliency of victims of traumatic events, as well as the concentration of disabling trauma in a minority (Miller \& Rasco, 2004; Wessells, 2006). Conclusions remain uncertain, however, because few studies consider endogeneity problems and measuring trauma and distress across cultures is challenging at best. Hollifield et al. (2002) review 394 studies of war trauma and conclude that most "are either descriptive or include quantitative data from instruments that have limited or untested validity and reliability."

Presurvey qualitative fieldwork suggested that disabling distress was the exception. Forty youth were selected for indepth interviews and assessments, including multiple interviews of the youth and his family, friends, teachers, and coworkers. These interviews suggested that aggression was low and that social reintegration and psychological resilience were widespread (Annan et al., 2008). Symptoms of distress that interfered with daily functioning, a defining element of psychological disorder, seemed to be concentrated in a minority and were not limited to former abductees.

Rather, in the minds of many of abducted youth and their families, the interruption of education and employment was of greater concern. Youth complained of difficulty reentering the school system, creating an education gap that limited their options in the labor market. According to one elder, "The youth who have not been abducted are engaged in different activities like business and vocational work like carpentry, because they had the opportunity to acquire the different skills."

Youth earn income mainly through small entrepreneurial activities. Some require little capital or skill (such as collecting firewood), while others require a little capital (hawking goods), moderate capital (a bicycle taxi), or substantial capital and skills (tailoring). This labor market is dynamic, and as youth accumulate skills and funds, they shift to more productive work. One youth began making charcoal from discarded wood. With his profits, he purchased a bicycle and began a taxi service, and with these profits, he educated himself and later opened a small store. Qualitatively, abduction appears to interrupt this accumulation of skills and capital and thus stalls productive employment. 
Figure 1.-Map of Uganda and Survey Field Site

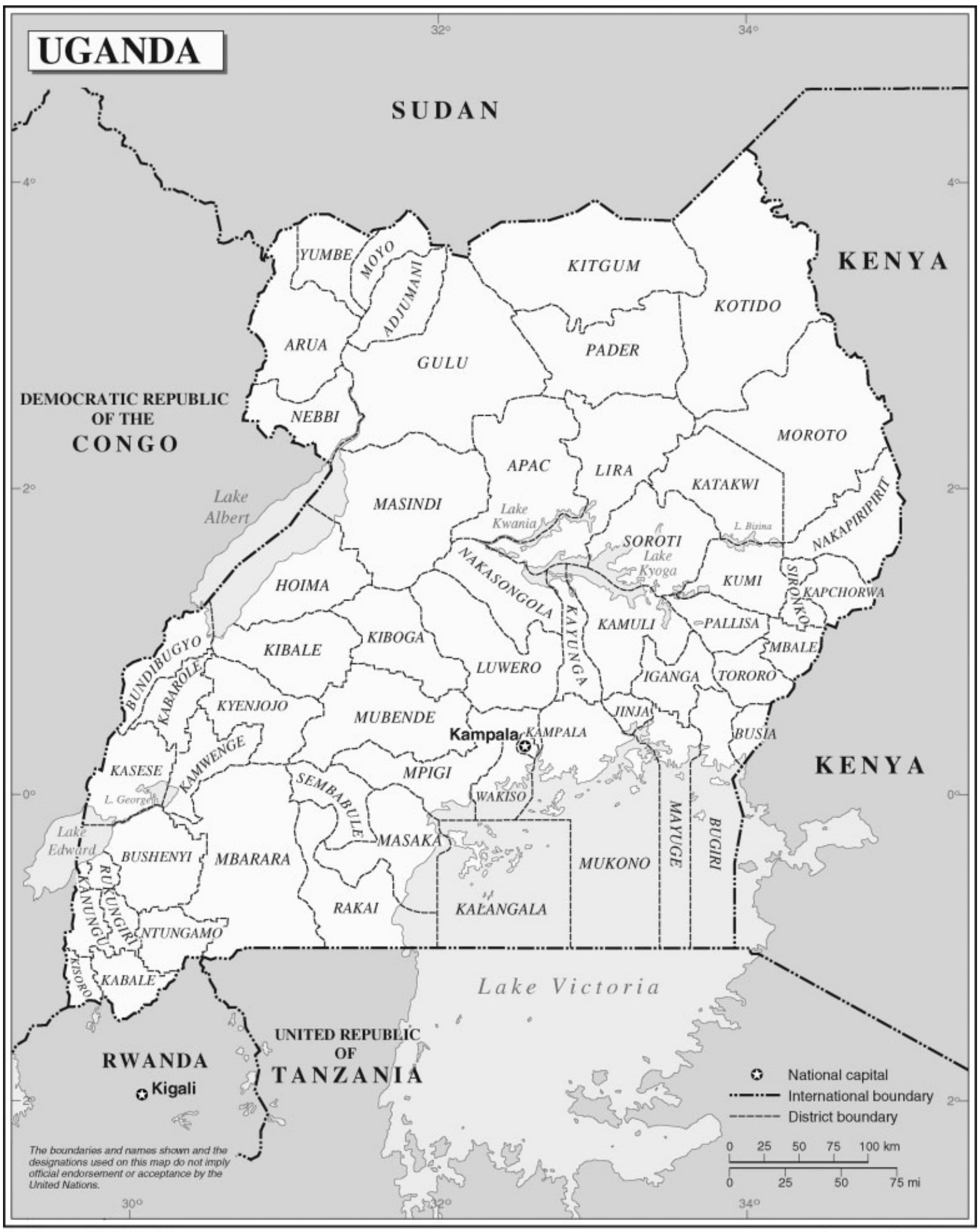




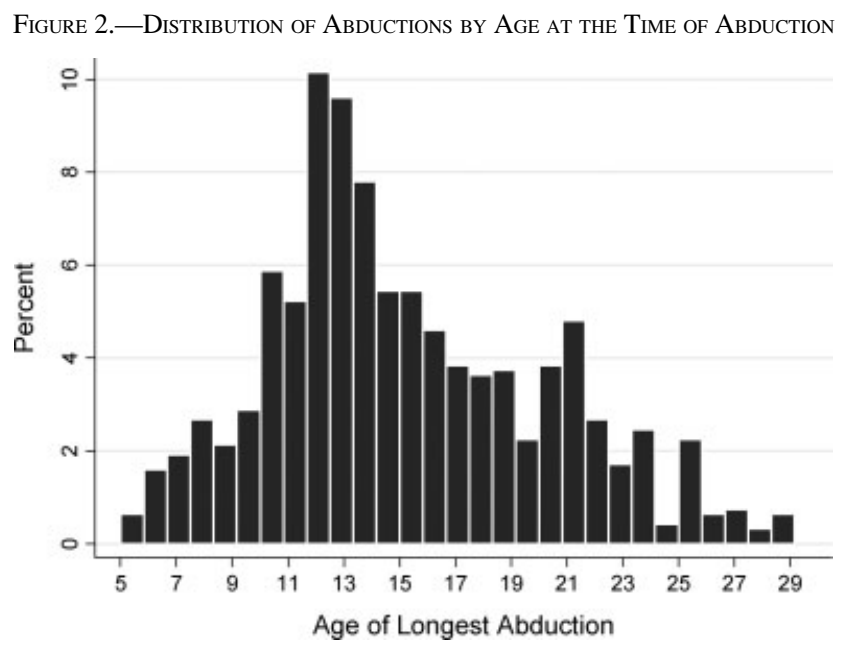

The bars represent a probability mass function for age at the time of longest abduction, and so sum to 1 . The data include absentee youth and youth who have since died or did not return from abduction (collected from the household survey).

\section{Data and Measurement}

In 2005 and 2006 we conducted phase 1 of the Survey of War Affected Youth (SWAY), a survey of 741 males born between 1975 and 1991 in one of eight rural subcounties in the districts of Kitgum and Pader. ${ }^{1}$ To minimize attrition from migration and mortality, we tried to identify a representative sample of youth living in the eight subcounties before the conflict. We randomly sampled 1,100 households from U.N. World Food Programme lists compiled in 2002. Ninety-three percent of these households were found, and Acholi enumerators worked with household heads to develop a roster of household members in $1996 .^{2}$ We chose the year 1996 because it was easily recalled as the date of the first election since 1980 and because it predates $85 \%$ of local abductions. A sample of 870 surviving male youth was drawn from this retrospective roster. Abductees were oversampled.

Of surviving males, $41 \%$ had moved since 1996, and enumerators attempted to track all migrants; 741 (84\%) were located, including all nonmigrants and $70 \%$ of migrants. We interviewed the families of all 129 unfound youth for data on abduction experiences and current out-

\footnotetext{
${ }^{1}$ Subcounties include 25 to 100 villages and range from 10,000 to 40,000 people. The eight subcounties represent roughly $10 \%$ of each district and $5 \%$ of all Acholi. These clusters were not selected randomly since poor security limited our team to subcounties that could be reached within a 90-minute drive from Kitgum and were visited regularly by our military escorts. We selected subcounties of varying size that seemed representative of the region as a whole.

2 These lists are an approximate census of the population since the entire population in each subcounty was displaced and receiving food aid. Based on interviews with local leaders, we believe that most households left family members in the camp, in part to receive the food aid. Hence these households' youth would be included in the sample frame. We estimate $5 \%$ of households left entirely and so do not enter the sample frame, introducing unknown selection.
}

comes and collected demographic data on the 349 youth who had died or not returned from abduction.

The 741 youth who completed the survey provided data on their war experiences as well as current well-being and outcomes. Key variables are described in table 1. Two aspects of these data are noteworthy. First, war experiences are self-reported and retrospective. ${ }^{3}$ Second, the measures of violence, social integration, hostility, and distress are additive indices of questions commonly used for measuring psychosocial well-being in conflict zones. Each is described in more detail below.

\section{Empirical Strategy}

We develop a comparison group of nonabducted youth in the war zone who for largely exogenous reasons were never abducted. We can interpret the difference in outcomes as the incremental effect of conscription in communities subjected to abduction. This counterfactual is a crucial one if we are interested in addressing reintegration gaps - that is, closing any inequality between combatants and noncombatants, or providing reparations beyond those received by other war-affected populations. We discuss the effects of war on nonabducted youth in section VII.

\section{A. Dealing with Endogenous Selection into the Armed Group}

The fundamental empirical problem we face is that we cannot observe an ex-combatant's well-being in the absence of abduction. The standard solution is the counterfactual approach, where a relevant control group is found and the average treatment effect (ATE) is estimated by taking the difference in the outcomes of the treated and controls (Rubin, 1974; Imbens \& Wooldridge, 2008). The estimated ATE is only as reliable as the counterfactual, of course, and it will be unbiased only when abduction and potential outcomes are independent.

In the case of ex-combatants, we are concerned that current differences are the result of prewar traits that led to selection into the armed group. To deal with such potential endogeneity, we look for situations where participation in the armed group is independent of outcomes conditional on observed prerecruitment variables. LRA abduction presents just such an unlikely case.

Interviews with LRA leaders suggest that the most common types of selection are not present. First, self-selection into the armed group was nonexistent in the subcounties we surveyed. The LRA's murder and mutilation of civilians in 1991 destroyed what little support the group ever enjoyed,

\footnotetext{
${ }^{3}$ We took several measures to guard against youth misrepresenting themselves as abductees (in the hopes of aid). We emphasized the absence of any link between the study and aid. Abduction data were also collected separately from the household head, and irregularities were investigated. Finally, the survey asked more than 200 detailed questions on abduction. Only 5\% of abductees raised suspicion, and reclassifying these has no material impact on our conclusions.
} 


\begin{tabular}{|c|c|c|c|c|}
\hline \multirow[b]{4}{*}{ Pretreatment Covariate } & (1) & (2) & (3) & (4) \\
\hline & \multicolumn{2}{|c|}{ Abducted versus Nonabducted } & \multicolumn{2}{|c|}{ Militia versus Nonmilitia Members } \\
\hline & \multicolumn{2}{|c|}{ Difference in Means ${ }^{b}$} & \multicolumn{2}{|c|}{ Difference in Means ${ }^{\mathrm{b}}$} \\
\hline & Unconditional & Conditional & Unconditional & Conditional \\
\hline Year of birth ${ }^{\mathrm{a}}$ & $1.02[0.44]^{* *}$ & $1.27[0.51]^{* *}$ & $2.76[0.82]^{* * *}$ & $2.31[0.65]^{* * *}$ \\
\hline Indicator for father a farmer ${ }^{\mathrm{a}}$ & $0.01[0.02]$ & $-0.01[0.02]$ & $0.06[0.04]$ & $0.05[0.04]$ \\
\hline Household size in $1996^{\mathrm{a}}$ & $-0.33[0.41]$ & $-1.51[0.32] * * *$ & $0.34[1.01]$ & $1.32[0.54]^{* *}$ \\
\hline Landholdings in $1996^{\mathrm{a}}$ & $0.57[2.09]$ & $-1.46[2.72]$ & $-6.69[4.13]$ & $-7.12[4.28]$ \\
\hline Indicator for top $10 \%$ of landholdings ${ }^{a}$ & $0.00[0.03]$ & $-0.02[0.03]$ & $-0.10[0.04]^{* *}$ & $-0.12[0.05]^{* *}$ \\
\hline Cattle in $1996^{\mathrm{a}}$ & $5.12[4.14]$ & $6.21[4.98]$ & $-10.07[6.18]$ & $-4.51[3.51]$ \\
\hline Other livestock in $1996^{\mathrm{a}}$ & $0.96[2.72]$ & $2.07[1.66]$ & $-6.25[2.60] * *$ & $-1.94[2.38]$ \\
\hline Indicator for plow ownership in $1996^{\mathrm{a}}$ & $0.03[0.07]$ & $-0.01[0.04]$ & $-0.18[0.08]^{* *}$ & $-0.06[0.04]$ \\
\hline Indicator for uneducated father & $0.01[0.02]$ & $0.02[0.02]$ & $-0.05[0.03]$ & $-0.12[0.04]^{* * *}$ \\
\hline Father's years of schooling & $-0.05[0.28]$ & $-0.06[0.30]$ & $-0.04[0.44]$ & $0.41[0.43]$ \\
\hline Indicator for uneducated mother & $-0.01[0.03]$ & $-0.01[0.04]$ & $0.09[0.08]$ & $0.05[0.10]$ \\
\hline Mother's years of schooling & $-0.10[0.26]$ & $-0.12[0.34]$ & $-0.44[0.41]$ & $-0.14[0.65]$ \\
\hline Indicator for paternal death before 1996 & $0.02[0.04]$ & $0.03[0.05]$ & $0.04[0.13]$ & $0.05[0.11]$ \\
\hline Indicator for maternal death before 1996 & $0.01[0.02]$ & $0.02[0.02]$ & $-0.07[0.04]^{*}$ & $-0.03[0.03]$ \\
\hline Indicator for orphaning before 1996 & $0.00[0.02]$ & $-0.02[0.02]$ & $-0.05[0.02]^{* *}$ & $-0.01[0.02]$ \\
\hline
\end{tabular}

and by the early 1990s, when Kony's forces expanded operations into Kitgum and Pader, abduction had become the sole means of recruitment. In fieldwork, it proved nearly impossible, even with the help of former rebel leaders, to find youth who voluntarily joined after 1991.

Second, LRA officers explained that by neither design nor accident did they abduct a select group. Typical of East Africa, rural Acholi households live in relative isolation, in the midst of their fields rather than in villages. This custom made them particularly vulnerable to the roving raiding parties. Rebels usually invaded homesteads at night, abducting all able-bodied civilians to carry loot. We interviewed roughly two dozen junior officers from the LRA who had returned under the amnesty. According to these raiding party leaders, targets were generally unplanned and arbitrary; they raided whatever homesteads they encountered, regardless of wealth or other traits. In essence, their strategy was to abduct first and sort out later. Junior officers were instructed to release young children and older adults, but to keep all adolescent and young adult males. Indeed, fewer than $5 \%$ of males abducted between the ages of 10 and 24 were released.

The survey data support these claims. We gathered retrospective data on prewar levels of household wealth (land, livestock, and plows), and parents' education, occupation, and death-measures that predict abduction in armed groups elsewhere in Africa (Cohn \& Goodwin-Gill, 1994; Honwana, 2005; Humphreys \& Weinstein, 2006). We observe little difference in prewar traits between the abducted and nonabducted, as seen by the unconditional and conditional mean differences in columns 3 and 4 of table 2. None of the unconditional differences in means except year of birth are significant at even a $10 \%$ level, and nearly all differences are close to 0 . Conditional mean dif- ferences, which control for all other pretreatment covariates, are generally small as well.

Abducted and nonabducted youth differ only in mean year of birth and mean prewar household size. This relationship between year of birth and abduction is expected, as a youth's probability of ever being abducted depended on how many years of the conflict he fell within the LRA's target age range. Moreover, abduction levels varied over the course of the war, so youth of some ages were more vulnerable to abduction than others. The significance of household size, meanwhile, is driven by households greater than 25 in number. We believe that rebel raiders, who traveled in small bands, were less likely to raid large, difficult-to-control households.

The distribution of predicted probabilities of abduction based on pretreatment data, in figure 3, offers more evidence of unconfoundedness. Probabilities are predicted from a logit regression of abduction on indicators for year and subcounty of birth, as well as all prewar household covariates. The predicted probabilities for abductees (the righthand panel) and nonabductees (the left-hand panel) overlap substantially. The difference in the abducted and nonabducted distributions is driven exclusively by year and subcounty of birth, and adding other prewar covariates leaves the distributions virtually undisturbed (an $F$-test of their joint significance yields a $p$-value of 0.40 ).

We can contrast LRA abduction to participation in local defense units (LDU), a militia under the Ugandan army command. Six percent of the sample is a current or past LDU member. Unlike abduction, prewar traits predict LDU participation; militia members come from poorer and more agricultural households (table 2, columns 3 and 4), and an $F$-test of all household characteristics yields a $p$-value of 0.05. The coefficients in the LDU regressions are also much 
Figure 3.-Distributions of the Predicted Probability of Abduction Based on Age and Location Alone versus All Pretreatment Covariates (by Abduction Status)

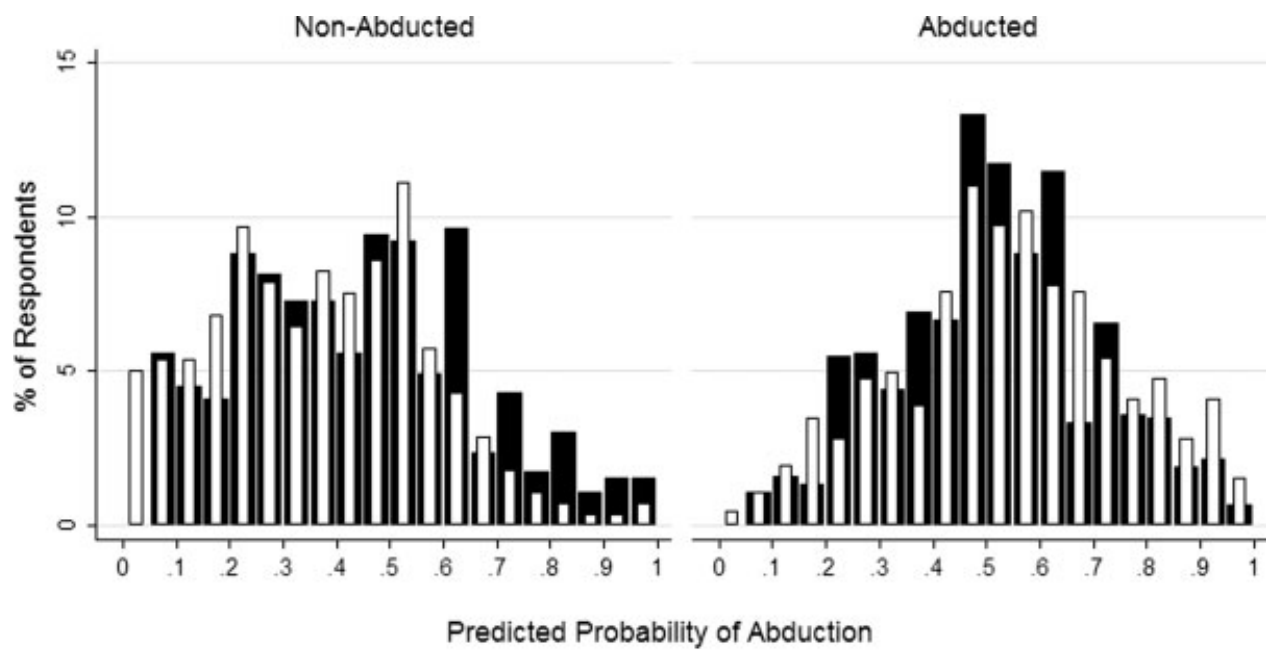

Age \& location dummies only

All pre-treatment covariates

$N=741$ males aged 14 to 30 , weighted by the inverse sampling probability and the inverse attrition probability. Pretreatment covariates other than age and location dummy variables include mother's and father's education, mother's and father's death in 1996, initial household landholdings and assets, and father's main occupation.

larger than when predicting abduction. Collectively, the results support the assumption of unconfounded abduction.

\section{B. Dealing with Selective Attrition and Survival}

The tracking success rate of this study meets or exceeds the rates achieved by several gold standard panel surveys in poor countries (Thomas, Frankenberg \& Smith 2001; Baird, Hamory \& Miguel, 2008; Humphreys \& Weinstein, 2008). Nevertheless, there are three main types of attritors: $12.4 \%$ of the 1996 sample migrated and were not found, $7.5 \%$ died, and $9.2 \%$ did not return from abduction (virtually all of whom can be presumed perished). Attrition patterns vary by treatment status: abductees are half as likely to be unfound migrants, twice as likely to have perished, and comprise all of those who did not return from abduction.

Attrition in large developing country panel surveys typically has little impact on coefficient estimates, even with attrition rates of $50 \%$ (Fitzgerald, Gottschalk, \& Moffitt, 1998; Falaris, 2003). Even so, we worry that attrition due to war deaths and nonreturn might be particularly selective. To correct for observable attrition, we used the data collected from surviving and found household members to predict attrition probabilities (Fitzgerald et al., 1998). ${ }^{4}$ All regression estimates are weighted by the inverse of these probabilities to eliminate bias from observed determinants of attrition.

\footnotetext{
${ }^{4}$ Data on attritors usually come from a prior round of survey data, while in this case, the data are provided by families. The third-party, retrospective nature of these data reduces the reliability of predicted attrition. The availability of data on current activity, however, is a distinct advantage over attrition-correction methods that rely on data from prior surveys.
}

Not all attrition determinants are observed. For instance, if abductees who died tended to be the weak or less clever, then the estimated ATEs will be biased toward 0. Moreover, those who remain with the armed group are likely missing more education and work experience than the average returnee, also contributing to potential underestimation of our economic and educational ATEs. Accordingly, we employ a method of sensitivity analysis proposed by Lee (2005) whereby best-case and worst-case scenarios for differential attrition are constructed by trimming the distribution of the outcome in the group with less attrition (in this case, the nonabducted).

\section{Estimation}

Assuming conditional unconfoundedness, the most efficient and consistent approach to ATE estimation is a weighted least squares (WLS) regression with weighting on the inverse of a nonparametric estimate of the propensity score (Hirano, Imbens, \& Ridder, 2003). Under WLS the regression function for outcome $Y$ is

$$
Y_{i}=\beta_{0}+\tau \cdot T_{i}+X_{i}^{S} \cdot \beta_{1}+\varepsilon_{i}
$$

where the treatment indicator $T$ equals 1 if youth $i$ was abducted, and the $X^{S}$ are the subset of covariates $X$ that are significantly correlated with $Y$, conditional on treatment. The weights used are

$$
\omega_{i}=\omega\left(T_{i}, v_{i}, \rho_{i}\right)=\rho_{i} \cdot \pi_{i} \cdot\left(\frac{T_{i}}{\hat{e}\left(v_{i}\right)}+\frac{1-T_{i}}{1-\hat{e}\left(v_{i}\right)}\right) .
$$

$\rho_{i}$ and $\pi_{i}$ are sampling and attrition weights, and $\hat{e}\left(v_{i}\right)$ is a nonparametric estimate of the propensity score. 
Table 3.-Estimates of the Average Treatment Effect of Abduction

\begin{tabular}{|c|c|c|c|}
\hline Dependent Variable & $\begin{array}{c}(1) \\
\text { ATE }\end{array}$ & $\begin{array}{c}(2) \\
\text { Nonabducted mean }\end{array}$ & $\begin{array}{l}(3) \\
\% \Delta\end{array}$ \\
\hline \multicolumn{4}{|l|}{ Educational and labor market outcomes } \\
\hline Years of education & $-0.75[0.17]^{* * *}$ & 7.6 & $-10 \%$ \\
\hline Indicator for functional literacy & $-0.15[0.04]^{* * *}$ & 0.80 & $-19 \%$ \\
\hline Indicator for any employment in the past month & $0.03[0.04]$ & 0.61 & $5 \%$ \\
\hline Indicator for capital- or skill-intensive work & $-0.05[0.02]^{* *}$ & 0.12 & $-43 \%$ \\
\hline Log (Daily wage) & $-0.33[0.15]^{* *}$ & n.a & n.a \\
\hline \multicolumn{4}{|l|}{ Psychosocial and health outcomes } \\
\hline Index of psychological distress & $0.57[0.20]^{* * *}$ & 3.8 & $15 \%$ \\
\hline Indicator for top quartile of distress & $0.11[0.04]^{* * *}$ & 0.23 & $49 \%$ \\
\hline Index of social support & $-0.16[0.14]$ & 5.5 & $-3 \%$ \\
\hline Indicator for hostile attitudes & $0.03[0.01]^{* *}$ & 0.07 & $40 \%$ \\
\hline Indicator for physical fights & $-0.02[0.02]$ & 0.07 & $-29 \%$ \\
\hline
\end{tabular}

Each entry represents a separate WLS regression. All variables defined and described in table 1 . *Significant at $10 \%$. **Significant at $5 \%$. ${ }^{* * *}$ Significant at $1 \%$. Treatment is binary and equals 1 if ever abducted and 0 otherwise. The percentage change $(\% \Delta)$ is calculated as the ATE relative to the mean value for nonabducted youth. Robust standard errors in brackets, clustered by sampling unit (location and abduction status). Controls in the WLS regressions include age and location dummies, age and location interactions, and pretreatment individual and household characteristics. Weighted by inverse sampling probability, inverse attrition probability, and inverse propensity score.

Note that the ATE estimated in equation (1) will be biased if abduction has positive or negative externalities on nonabducted youth. We address this concern after seeing the results.

\section{The Impacts of Abduction}

\section{A. Average Treatment Effects}

Abduction ATEs for ten outcomes are listed in table 3. Each entry in column 1 represents the coefficient on an abduction indicator, column 2 lists the mean level of each outcome among nonabducted youth, and column 3 calculates the proportional impact of the ATE relative to the nonabducted mean. ${ }^{5}$ All results are robust to alternative specifications and controls. ${ }^{6}$

Educational and labor market impacts. Abducted male youth attain 0.75 fewer years of education, a $10 \%$ reduction relative to the average nonabducted youth's 7.6 years of education. This schooling loss corresponds closely to the average length of abduction-8.9 months, or 0.74 of a year. The abducted are also 15 percentage points less likely to report being functionally literate (able to read a book or newspaper), implying that abductees are nearly twice as likely to be illiterate than nonabductees. ${ }^{7}$

\footnotetext{
${ }^{5}$ We control for year and location (subcounty) of birth with dummy variables for year and location, as well as year and location interactions. Also included are quartic terms for each pretreatment household characteristic. Matching estimates match one-for-one exactly on location and four-year age intervals, followed by matching on specific age.

${ }^{6}$ Results are robust to the removal of the selection-correction weights; the further exclusion of prewar household characteristics, the removal of attrition-correction weights, and the exclusion of the age and location dummy variables (a simple difference of means between treatment and control groups). The results are also robust to the use of a nonparametric matching estimator.

${ }^{7}$ This literacy ATE seems large given the ATE in schooling. In local primary schools, however, pupils learn to read only by their sixth or seventh year of school, and losing these crucial years dramatically increases illiteracy. For instance, looking at all youth in the sample, moving from 6 to 7 years of schooling is associated with a 22 percentage point increase in literacy.
}

Labor market performance also suffers due to abduction, but in the quality of work rather than the quantity. Abducted and nonabducted youth display little difference in the probability of having any work. Work found by abductees, however, is of a lower skill and capital intensity. Eight percent of all youth are engaged in a profession or a vocation or own their own small business. Abducted youth, however, are five percentage points $(43 \%)$ less likely than nonabducted youth to be engaged in such skilled work. The wage ATE also implies that the abducted are less productive. Wages are proxied by the total gross earnings reported in the previous four weeks, divided by days employed in the month. Using the log of this wage proxy, the ATE can be interpreted as the approximate percentage change in wages due to abduction. The results suggest that wages are $33 \%$ lower among abducted youth. ${ }^{8}$

Psychosocial outcomes. We adapt a measure of social support using an additive index of fourteen concrete forms of support received from family and friends in the previous month (such as someone lending you things, praising you, giving you advice, or helping you find work), based on Barrera, Sandler, and Ramsay (1981). The average youth reported 5.5 such forms of support. From table 3, we see little substantive or statistically significant difference between abducted and nonabducted youth. Moreover, the abducted are just as likely to report membership in a church or community organization (results not displayed).

We also examine aggression. One risk of combat is that participants are socialized into violence. We measure aggression with two indicators: one for whether the youth reported being in a physical fight in the past six months

\footnotetext{
${ }^{8}$ Wages are not observed for 237 unemployed youth (and log wages are undefined for 56 males with zero earnings). If abduction is associated with the propensity to be employed or earn nothing, we will conflate the direct impact of abduction on wages with the indirect effects on the type of people employed (Heckman, 1979; Lee, 2005). Since abduction is uncorrelated with employment and the likelihood of zero earnings, such sample selection bias is likely immaterial.
} 
(6.7\% overall) and a second for self-reported aggressive behaviors, such as being quarrelsome, threatening others, and using abusive language (7.2\%). As seen in table 3, abductees were slightly less likely to have been in a fight, although the result is not statistically significant. Abductees are, however, 3 percentage points more likely to report aggressive behaviors-40\% greater than nonabducted youth. These results may indicate greater hostility among abductees. This result, however, is fragile and disappears in almost any other specification. Thus we conclude with great caution that moderate aggression results from abduction.

Not only is there little evidence that abductees are social pariahs; the opposite may be true. Blattman (2009) uses the same survey and empirical strategy to assess the political legacies of violent conflict. Former abductees are $28 \%$ more likely to have voted in a 2005 national referendum, 106\% more likely to be a community organizer (an elected position common among youth), and $160 \%$ more likely to hold a position of political leadership.

Finally, we adapt an additive index of psychological distress using seventeen self-reported symptoms of depression and anxiety (including traumatic stress). ${ }^{9}$ The mental health measures and results, including risk and protective factors, are discussed in depth by Annan and Blattman (2009). We highlight key results here to provide a complete picture of abduction. The average youth has a score of 4 (on a potential scale of 17). The highest score in our sample is 15 . No norms or scores to determine clinically significant levels of symptoms have been established in this population, and so the severity of the average index value is open to subjective interpretation. A score of 4 indicates a range of symptom profiles, from a youth experiencing approximately four symptoms (such as nightmares, difficulty concentrating) frequently to having thirteen symptoms of these symptoms on rare occasion. ${ }^{10}$ On other standard scales, this number of symptoms falls below the clinical cut-off or in a mild to moderate range of depression or anxiety (Beck, Steer, \& Garbin, 1988).

Abductees exhibit a 0.57 point increase in the distress index-an increase of roughly $15 \%$ relative to the nonabducted average of 3.8 (see table 3 ). This ATE could imply an increase in the frequency of a single symptom of distress from rarely to often, or the addition of two symptoms, from rarely to sometimes. The effect size (mean difference divided by standard deviation) is 0.21 , indicating that the

\footnotetext{
${ }^{9}$ We adapt our scale from the Northern Ugandan Child and Youth Psychosocial Adjustment Scale (MacMullin \& Loughry, 2002). Each symptom is scaled between 0 and 1 according to its reported intensity. For each symptom, "often" receives a value of 1 , "sometimes" 0.66 , "rarely" 0.33 , and "never," 0 . We construct the index of distress using factor analysis and employ a standard procedure in the psychological literature: symptoms with factor loadings over 0.3 are included in the index additively (Fabrigar et al., 1999). Our results are robust to other index constructions.

${ }^{10}$ The six most commonly reported symptoms are "excessive worrying," "bad memories from the past," "difficulty concentrating," "finding life difficult," "crying when remembering bad memories," and "restless nights."
}

Figure 4.-Quantile Differences in the Distribution of Psychological Distress between Abducted AND Nonabducted Youth

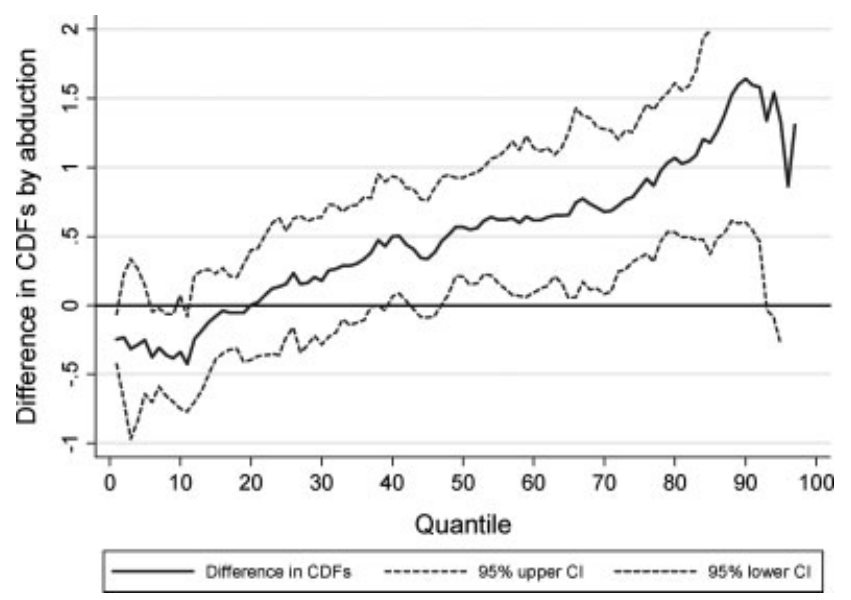

The solid line is calculated from the coefficients on the abduction indicators from least absolute deviation (quantile) regressions of the index of psychological distress on an abduction indicator and controls, at every quantile of the distribution. Controls include age, location dummies and interactions, as well as pretreatment covariates. Extreme values of the confidence interval (above 2 and below 1) are not displayed, for clarity.

mean of the abducted group is at approximately the 58th percentile of the nonabducted group and that there is a great deal of overlap between the two groups.

The youth who exhibit the most symptoms of distress, however, are disproportionately abductees. Abducted youth are 11 percentage points more likely to be in the top quartile of the distress index-a $49 \%$ increase relative to the nonabducted. Nearly $37 \%$ of former abductees report reexperiencing traumatic events through nightmares versus $25 \%$ of nonabducted youth. Furthermore, $16 \%$ of abductees report feeling "always sad" compared to $13 \%$ of their nonabducted peers.

These findings suggest that we should be interested in the distribution of psychological outcomes, especially the top tail. Figure 4 illustrates the difference in distress levels of abductees and nonabductees at each quantile of the conditional distribution of distress. This difference is equivalent to the horizontal distance between the age and locationadjusted distributions of distress for abducted and nonabducted youth at each percentile. The median abducted youth exhibits a distress score that is 0.57 points greater than the median nonabducted youth (who has a score of 3.3). An abducted youth at the 90th percentile of his distribution, however, reports 1.6 more symptoms of distress than a nonabducted youth in the same position.

\section{B. Caveats}

Several caveats are in order. First, abduction reflects a heterogeneous mix of experiences, and so it is not clear what is our "treatment" and whether these ATEs are generalizable. Below we unpack the treatment effect according to specific war experiences such as age, length, and violence. 
Second, outcomes may be mismeasured or misreported. One concern is that underreporting of distress symptoms among the most distressed would lead us to underestimate treatment effects. Without established clinical norms in this population, we are unable to assess possible underreporting of distress symptoms (although underreporting due to repression or avoidance is unlikely). ${ }^{11}$ Nevertheless, even substantial underestimation is unlikely to change the basic conclusion: that the average (or median) increases in reported distress of abducted youth are moderate and that the highest symptoms of distress are disproportionately concentrated in abductees.

Finally, the moderate average psychological impacts could be a consequence of the success of humanitarian programs provided to former abductees. If so, our results would underestimate the psychosocial impact of abduction. This scenario is unlikely, as reintegration programs have been modest in scale and reach: only half of abductees passed through the formal care system, and those who did pass through the centers received only basic medical treatment, family reunification, and advice from social workers. Receipt of NGO services, moreover, is uncorrelated with levels of psychological distress. The estimates presented in this paper thus reflect the impact of combat conditional on half of abducted youth receiving the most rudimentary reintegration services.

\section{Externalities from Abduction}

What do our treatment effects mean when the counterfactual group, nonabducted youth, is still affected by war? Nonabductees in raided areas could have worse schooling outcomes due to fewer schools being open, fewer teachers available, and general income shocks to the household. If they exist, such negative externalities will lead us to underestimate the true impact of abduction. Or abductions and displacement could lead to positive externalities as nonabducted populations are urbanized in displacement camps (closer to schools) or displaced to towns (closer to markets). Excessive displacement into towns could account for the higher levels of skilled work and wages we see among nonabducted youth.

To test for externalities, we calculate a measure of abduction intensity, the proportion of the parish population aged 7 to 40 ever abducted, in each of the 36 parishes that comprise our eight subcounties. Intensity, which ranges from $8 \%$ to $32 \%$, is uncorrelated with well-being among nonabducted youth. Table 4 displays the coefficient on abduction intensity in regressions of each outcome on intensity, year and location of birth, and prewar controls. Greater intensity cor-

\footnotetext{
${ }^{11}$ Repression of traumatic memories tends to occur among younger children than our sample. Moreover, even if a youth actively avoids traumatic memories, this repression will often manifest itself in other symptoms. Finally, while distress may manifest itself long after the event, most people respond immediately (American Psychiatric Association, 2000).
}

TABle 4.- Spillover EfFects of Abduction Intensity

\begin{tabular}{|c|c|}
\hline & $\begin{array}{c}\text { Correlation between } \\
\text { Outcome and } \\
\text { Parish-Level } \\
\text { Abduction Intensity }\end{array}$ \\
\hline \multicolumn{2}{|l|}{ Educational and labor market outcomes } \\
\hline Years of education & $-0.02[0.04]$ \\
\hline Indicator for functional literacy & $0.00[0.01]$ \\
\hline Indicator for any employment in the past month & $0.01[0.01]$ \\
\hline Indicator for capital- or skill-intensive work & $0.00[0.01]$ \\
\hline Log (Daily wage) & $-0.04[0.02]$ \\
\hline \multicolumn{2}{|l|}{ Psychosocial and health outcomes } \\
\hline Index of psychological distress & $0.03[0.03]$ \\
\hline Indicator for top quartile of distress & $0.01[0.01]$ \\
\hline Index of social support & $-0.10[0.04]^{* *}$ \\
\hline Indicator for hostile attitudes & $0.00[0.00]$ \\
\hline Indicator for physical fights & $-0.01[0.00]$ \\
\hline \multicolumn{2}{|l|}{ Migration outcomes } \\
\hline Migrated to a town & $0.00[0.00]$ \\
\hline Migrated out of home district & $0.00[0.00]$ \\
\hline Migrated to town outside home district & $0.00[0.00]$ \\
\hline
\end{tabular}

Each entry represents a separate WLS regression of the outcome on abduction risk, year and location of birth, and prewar traits. Abducted youth are omitted from the analysis. Robust standard errors in brackets, clustered by sampling unit (location and abduction status. *Significant at $10 \%$. **Significant at $5 \%$. *** Significant at $1 \%$.

relates with lower education, higher employment, lower wages, higher distress, and lower aggression among nonabductees, but not statistically significantly so. Abduction intensity is strongly correlated with lower social support, however-significant at the 5\% level. Yet we see no difference in social support between abducted and nonabducted youth. It may be that abductions displace and disperse social networks, but for all war victims and abductees equally. We see no evidence of spillovers in the outcomes where abductees performed more poorly than nonabducted youth.

We also see no effect of abduction intensity on displacement to towns or other districts. The majority of the population was displaced to rural displacement camps, but some migrated in search of work. Table 4 displays the correlations between intensity and an indicator for migrating to a town, outside the district, or to a town outside the district (none being mutually exclusive). Nonabducted youth were more likely to migrate, and those who did earned higher wages than their rural counterparts. But this migration does not appear to have been a direct spillover of abduction intensity.

\section{Child versus Adult Combatants}

What's special about being a child soldier? To see, we compare impacts by age of abduction, which ranges from 5 to 29 . We regress each outcome on age of abduction while controlling for location of birth indicators, as well as indicator variables for the year of abduction (to control for any possible changes in abduction patterns and experiences over time). The results, displayed in table 5, suggest little significant difference in outcomes for children versus adult abductees.

The absence of any significant relationship among education, wages, and age of abduction is surprising, especially 
Table 5.-Variation in the Average Treatment Effect by Age of Abduction

\begin{tabular}{|c|c|c|}
\hline Dependent Variable & $\begin{array}{c}\text { WLS Coeffcient } \\
\text { on Age of } \\
\text { Abduction }\end{array}$ & Observations \\
\hline \multicolumn{3}{|l|}{ Educational and labor market outcomes } \\
\hline Years of education & $0.00[0.04]$ & 462 \\
\hline Indicator for functional literacy & $0.00[0.01]$ & 462 \\
\hline $\begin{array}{l}\text { Indicator for any employment } \\
\text { in the past month }\end{array}$ & $-0.01[0.01]$ & 462 \\
\hline $\begin{array}{l}\text { Indicator for capital- or skill- } \\
\text { intensive work }\end{array}$ & $0.00[0.01]$ & 462 \\
\hline Log (Daily wage) & $-0.03[0.02]$ & 288 \\
\hline \multicolumn{3}{|l|}{ Psychosocial and health outcomes } \\
\hline Index of psychological distress & $-0.02[0.03]$ & 462 \\
\hline Indicator for top quartile of distress & $0.00[0.01]$ & 462 \\
\hline Index of social support & $-0.05[0.04]$ & 462 \\
\hline Indicator for hostile attitudes & $0.00[0.00]$ & 462 \\
\hline Indicator for physical fights & $0.00[0.00]$ & 462 \\
\hline
\end{tabular}

in light of the employment coefficient. Younger abductees are more easily influenced and indoctrinated by the LRA, and so are more likely to remain (the average abduction length is ten months for those under age 18 versus six months for those of age 18 or older). Furthermore, younger abductees are more likely to be enrolled in school at the time of abduction, and so more likely to have their education interrupted. As a result, we would expect to see greater educational and labor market impacts for child soldiers than adult ones. One reason we see little variation in outcomes by age is that younger abductees are more likely to return to school on return: two-thirds of youth abducted before the age of 18 return to school versus less than a third of those abducted over that age. Thus, longer abductions may be offset by ease of reintegration.

\section{E. Sensitivity Analysis}

A remaining concern is the potential for unobserved selection and bias. Several plausible sources exist, including youth self-selecting out of the LRA by a better ability to hide from the rebels or survival of only the physically strongest. We are especially worried about the selection of lowability recruits into the rebel group or from differentially greater attrition of high-ability recruits, leading to overestimation of the ATEs.

Sensitivity to violations of unconfoundedness. To assess the potential for unobserved selection, we explicitly model relaxations of unconfoundedness. An unobserved covariate, $U$, will induce a material degree of bias only if it is sufficiently associated with both treatment assignment, $T$, and the outcome, $Y$. We model a hypothetical $U$ with a given distribution and calculate the combinations of correlation between $U$ and $T$ and between $U$ and $Y$ that would lead our ATE estimate to be biased by a fixed amount and benchmark this unobservable using observed covariates, $X$.
Figure 5.-Impact of RelaXing the Assumption of UnConfoundedness

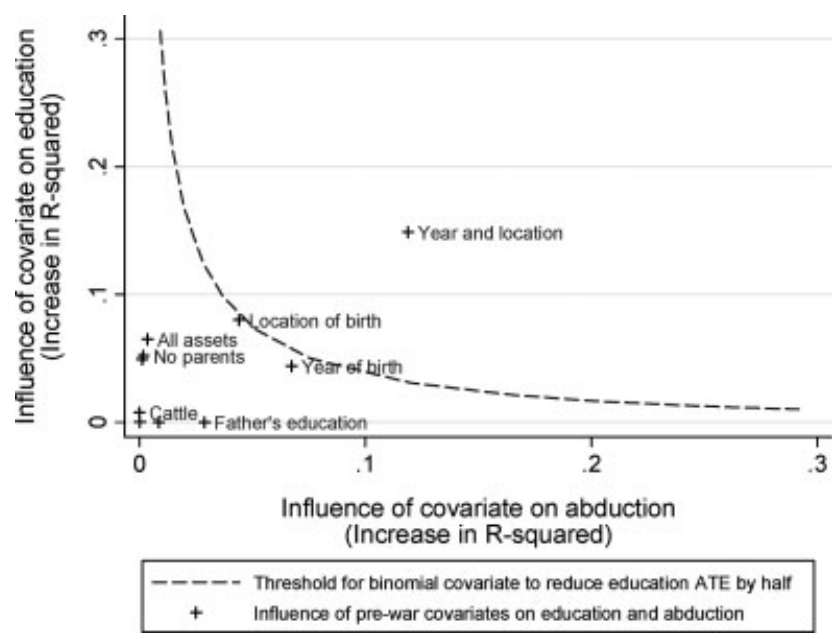

Results of the sensitivity analysis following Imbens (2003). Each + represents a prewar covariate, plotted according to its additional explanatory power for treatment assignment (on the horizontal axis) and its explanatory power for the outcome (vertical axis), which in this case is educational attainment. Each axis measures the change in the $R^{2}$ statistic from adding that covariate to the regression. The curve represents the locus of points at which any independent binomial covariate (observed or unobserved) would have sufficient association with both treatment and educational outcomes to reduce the ATE on education by half.

(Rosenbaum \& Rubin, 1983; Imbens, 2003). We employ a parametric model postulating an independent binomial distribution for $U$, a logistic conditional distribution for $T$, and a normal conditional distribution for $Y$.

Figure 5 plots each of the observed prewar controls according to their ability to explain variation in both $T$ (abduction) and $Y$ (in this case, education). The vertical axis charts the influence of each covariate in explaining variation in years of education and represents the marginal increase in the $R^{2}$ statistic from adding the covariate to a regression of education on all other covariates. The horizontal axis indicates the influence of each covariate in explaining additional variation in abduction. With the exception of age and location, the observed covariates explain little variation in either $Y$ or $T$.

The curve in figure 5 represents all the combinations of correlation between $U$ and $T$ and between $U$ and $Y$ that would be sufficient to reduce the estimated education ATE by half. The curve is therefore a threshold, beyond which the hypothetical $U$ is influential enough to materially reduce the education ATE. It is also a threshold, incidentally, that would leave the sign and significance of the ATE (and hence our general policy conclusion) intact. Only year and location of birth - the primary determinants of selection by the armed group-meet or cross this hypothetical threshold. ${ }^{12}$ Meanwhile, traits that normally influence military recruitment (such as household wealth or orphaning) lie well beneath the threshold.

\footnotetext{
${ }^{12}$ Year of birth also influences treatment assignment mechanically (as abduction levels changed year to year) as well as because rebel abduction parties targeted adolescents. Thus, its distance from the origin in figure 5 overstates the role of age as a selection criterion.
} 
Table 6.-Treatment Effect Bounding for Selective Attrition

\begin{tabular}{|c|c|c|c|c|c|}
\hline \multirow[b]{3}{*}{ Dependent Variable } & (1) & (2) & (3) & (4) & $(5)$ \\
\hline & \multicolumn{2}{|c|}{$\%$ Missing Data ${ }^{a}$} & \multicolumn{3}{|c|}{ Treatment Effect Bounds ${ }^{c}$} \\
\hline & $\begin{array}{c}\text { Not } \\
\text { Abducted }\end{array}$ & Abducted & $\begin{array}{l}\text { Untrimmed } \\
\text { ATE }^{\mathrm{b}}\end{array}$ & $\begin{array}{c}\text { "Best Case" } \\
\text { Attrition Bound }\end{array}$ & $\begin{array}{l}\text { "Worst Case" } \\
\text { Attrition Bound }\end{array}$ \\
\hline \multicolumn{6}{|l|}{ Educational and labor market outcomes } \\
\hline Years of education & $11 \%$ & $23 \%$ & $-0.53[0.20]^{* *}$ & $-1.19[0.24]^{* * *}$ & $0.23[0.24]$ \\
\hline Indicator for functional literacy & $11 \%$ & $23 \%$ & $-0.12[0.03]^{* * *}$ & $-0.23[0.04]^{* * *}$ & $-0.09[0.03]^{* * *}$ \\
\hline Indicator for any employment in the past month & $11 \%$ & $23 \%$ & $0.11[0.03]^{* * *}$ & $0.17[0.04]^{* * *}$ & $0.03[0.04]$ \\
\hline Indicator for capital- or skill-intensive work & $28 \%$ & $30 \%$ & $-0.04[0.02]$ & $-0.05[0.02]$ & $-0.02[0.04]$ \\
\hline Log (Daily wage) & $59 \%$ & $54 \%$ & $-0.13[0.12]$ & $-0.38[0.15]^{* *}$ & $0.14[0.15]$ \\
\hline \multicolumn{6}{|l|}{ Psychosocial and health outcomes } \\
\hline Index of psychological distress & $28 \%$ & $30 \%$ & $0.56[0.17]^{* * *}$ & $0.71[0.30]^{* *}$ & $0.49[0.22]^{* *}$ \\
\hline Indicator for top quartile of distress & $28 \%$ & $30 \%$ & $0.13[0.03]^{* * *}$ & $0.15[0.05]^{* * *}$ & $0.12[0.04]^{* * *}$ \\
\hline Index of social support & $28 \%$ & $30 \%$ & $-0.10[0.19]$ & $-0.20[0.27]$ & $0.05[0.28]$ \\
\hline Indicator for hostile attitudes & $28 \%$ & $30 \%$ & $0.03[0.02]$ & $0.05[0.04]$ & $0.03[0.02]$ \\
\hline Indicator for physical fights & $28 \%$ & $30 \%$ & $0.00[0.02]$ & $0.02[0.04]$ & $-0.01[0.02]$ \\
\hline \multicolumn{6}{|c|}{$\begin{array}{l}\text { Each row represents the results of the trimming procedure suggested by Lee (2005) to account for selective attrition and survival. Treatment is binary and equals } 1 \text { if ever abducted and } 0 \text { otherwise. Standard errors } \\
\text { brackets, but are not clustered or heteroskedastic-robust. All estimates are weighted by inverse sampling probabilities and inverse propensity scores. *Significant at } 10 \% \text {. **Significant at } 5 \% \text {. ***Significant at } 1 \% \text {. } \\
\text { a Missing youth include attritors and nonsurvivors; } 31 \% \text { of nonabducted youth and } 30 \% \text { of abducted youth are missing. Data collected from families on the education, employment status, and major injuries of } \\
\text { igrant youth reduce these mising percentages to } 14 \% \text { and } 23 \% \text {. In the case of wages, additional observations are missing due to unemployed youth. } \\
\text { b The untrimmed ATE is the difference in the weighted means of the abducted and nonabducted groups and is not a regression estimate. No control variables are used. } \\
{ }^{c} \text { Best and worst-case bounds are calculated as the difference in the weighted means of the abducted and nonabducted groups after trimming the top or the bottom of the distribution of the outcome variable in the } \\
\text { eatment group with less attrition. They are not regression estimates. }\end{array}$} \\
\hline
\end{tabular}

Bounding the treatment effect for selective survival and nonreturn. Table 6 displays rates of attrition and attrition bounds for each outcome using the Lee (2005; Rosenbaum \& Rubin, 1983) method. The best-case scenario bound is calculated by dropping nonabductees with the lowest values of the outcome and calculating the trimmed ATE. The worst-case bound is calculated by dropping the best-performing nonabducted youth (the worst case is one where the untrimmed ATE erroneously leads us to conclude the existence of an ATE different from 0). Lee's method compares the untrimmed ATE (column 3) to the trimmed means (columns 4 and 5). The ATEs under the worst-case scenario are generally closer to 0 and less than robust than the untrimmed ATEs. By the standards of this sensitivity analysis, this worst-case performance is actually quite strong, since not one of these lower bounds changes sign. The loss of statistical significance is not uncommon. The results imply that under austere and implausible dramatic selection, abduction still has the predicted effect on outcomes, albeit at a lower level of statistical significance.

\section{Heterogeneous Treatments and the Channel of Impact}

Abduction has so far been handled as a binary treatment. This approach, however, obscures the diversity of experiences and the true treatment received. In particular, abduction length ranged from 1 day to 10 years, and violence varied dramatically. When treatment is heterogeneous, the binary ATE can be interpreted as the average per unit effect along a response function mapping treatment exposure to outcomes (Angrist \& Imbens, 1995). One might prefer, however, to estimate the entire response function, considering abduction length or violence the "true" treatment.
Treatment exposure, however, is likely to be endogenous. Longer or more violent abductions, while idiosyncratic to some degree, are undoubtedly related to unobserved individual traits, even if abduction itself is not. Even so, estimating the (potentially biased) relationship between our measures of treatment exposure and outcomes is useful for understanding the underlying causal channels and is more easily generalized.

\section{A. Psychosocial Outcomes}

The evidence suggests that youth who exhibit the most serious symptoms of psychosocial distress are generally those who experienced the greatest war violence, as discussed in detail by Annan and Blattman (2009). Table 7 displays regression of each outcome on three measures of abduction intensity: years abducted (column 1), an index of seventeen violent acts experienced (column 2), and an index of eight violent acts perpetrated (column 3). The indices of violence are linear and additive, based on selfreported indicators for six different acts witnessed by the youth (for example, rape and killings of others), six acts inflicted on the youth himself (for example, beatings, imprisonment), and five acts on his family (for example, abduction, war injury, killing). Acts perpetrated include theft, beatings, killings, and rape.

After controlling for violence, longer abductions are not robustly associated with higher distress. Each additional incident of violence experienced, however, is associated with a 0.15 point increase in our distress index, while acts perpetrated are associated with a 0.27 point increase in distress. The average abductee reported 4 more violent acts experienced and 1.4 more perpetrated than nonabductees (table 1), implying a distress impact of 0.98 . 
Table 7.-Estimates of the Impact of Abduction Length AND Violence On Outcomes

\begin{tabular}{|c|c|c|c|}
\hline \multirow[b]{3}{*}{ Dependent Variable } & \multirow[t]{2}{*}{ (1) } & \multirow{2}{*}{$\frac{(2)}{\text { Coefficient on }}$} & \multirow[t]{2}{*}{ (3) } \\
\hline & & & \\
\hline & $\begin{array}{c}\text { Years } \\
\text { Abducted }\end{array}$ & $\begin{array}{l}\text { Index of Violence } \\
\text { Experienced }\end{array}$ & $\begin{array}{c}\text { Index of Violence } \\
\text { Perpetrated }\end{array}$ \\
\hline \multicolumn{4}{|l|}{ Educational and labor market outcomes } \\
\hline Years of education & $-0.54[0.090]^{* *}$ & $-0.05[0.043]$ & $0.11[0.089]$ \\
\hline Indicator for functional literacy & $-0.09[0.021]^{* *}$ & $-0.01[0.007]$ & $0.02[0.012]$ \\
\hline Indicator for any employment in the past month & $0.00[0.014]$ & $-0.01[0.013]$ & $0.01[0.015]$ \\
\hline Indicator for capital- or skill-intensive work & $-0.01[0.010]$ & $0.00[0.004]$ & $-0.01[0.009]$ \\
\hline Log (Daily wage) & $0.02[0.046]$ & $-0.08[0.023]^{* *}$ & $0.04[0.052]$ \\
\hline \multicolumn{4}{|l|}{ Psychosocial and health outcomes } \\
\hline Index of psychological distress & $-0.03[0.103]$ & $0.15[0.034]^{* *}$ & $0.27[0.080]^{* *}$ \\
\hline Indicator for top quartile of distress & $-0.01[0.020]$ & $0.03[0.007]^{* *}$ & $0.01[0.014]$ \\
\hline Index of social support & $-0.11[0.062]$ & $0.11[0.058]$ & $0.04[0.118]$ \\
\hline Indicator for hostile attitudes & $0.00[0.007]$ & $0.00[0.004]$ & $0.00[0.008]$ \\
\hline Indicator for physical fights & $0.00[0.009]$ & $0.00[0.005]$ & $0.01[0.007]$ \\
\hline
\end{tabular}

include year and location of birth dummies, prewar characteristics, and year of abduction dummies. Nonabducted youth are omitted from the regression. *Significant at $10 \%$. **Significant at $5 \%$ *** Significits $1 \%$.

Such a link between increased exposure to violence and higher emotional distress has been identified among waraffected populations in settings as diverse as Iraq, Cambodia, Rwanda, and Croatia (Kinzie et al., 1986; Sack et al., 1986; Mollica et al., 1997; Ajdukovic \& Ajdukovic, 1998; Dyregrov et al., 2000; Dyregrov, Gjested, \& Raundalen, 2002). Violence rather than abduction is the underlying "treatment" resulting in distress.

Turning to social support, our index is decreasing in abduction length. An obvious possibility is that longer lengths of time away reduce social and family ties. Finally, there is no robust association between our two measures of aggression and abduction length or violence: the coefficients are close to 0 and not statistically significant.

\section{B. Educational and Labor Market Outcomes}

Time away from human capital accumulation rather than violent trauma may account for the persistent educational effects of abduction. Long abductions are strongly correlated with losses in education and literacy: each year of abduction is associated with 0.54 years less education and a 9 percentage point reduction in literacy. The association between violence and education is fairly weak. One interpretation is that when it comes to education, the relevant "treatment" may not be violence but rather the interruption of schooling and work experience. An alternative is that more educated abductees are able to escape more quickly, leading to upward bias in the coefficient on abduction length. Both could be at work, but only the former could account for the average adverse impact of abduction on education we saw in table 3 .

The correlates of wages suggest that time away from education could also be the main driver of the wage gap between abducted and nonabducted youth. Consider a human capital earnings function where wages are a log-lin- ear function of education, experience, social capital, and health: ${ }^{13}$

$$
\begin{aligned}
\ln \left({\text { Wage })_{i}=\delta_{0}}_{1}\right. & +\delta_{1} \cdot \text { Education }_{i}+\delta_{2} \cdot \text { Experience }_{i} \\
& +\delta_{3} \cdot \text { Social Capital }_{i}+\delta_{4} \cdot \text { Health }_{i}+\mu_{i}
\end{aligned}
$$

We estimate this equation in column 1 of table 8 using the index of social support, an injury indicator, and the index of distress as proxies for social capital, physical, and mental health. These estimates suggest that education and health are the strongest observed correlates of wages. ${ }^{14}$

We can obtain a rough measure of the relative influence of each component of human capital in the abduction wage gap by multiplying the earnings function coefficients by the respective abduction ATEs (table 8, columns 2 and 3). ${ }^{15}$ Education, as the strongest determinant of wages (and a principal casualty of abduction), appears to be the most significant channel by which abduction reduces wages, representing $55 \%$ of the reduced-form ATE for log wages (column 4). While this estimate is crude and undoubtedly biased, it is more than three times as influential as the experience and physical health measures. Even if dramatically biased, the basic conclusion is the same.

\footnotetext{
${ }^{13}$ See Mincer (1974) for the theoretical justification of this function. Experience is calculated as Age -6 - Education.

${ }^{14}$ Potential measurement error and bias from omitted variables prevent a causal interpretation of these coefficients. International evidence on returns to schooling, however, suggests that the education coefficient is likely to be correct to a first order of approximation. For a discussion of estimation bias regarding schooling, see Card (1999) and for health, see Strauss and Thomas (1998). The literature suggests that ability and attenuation biases are moderate and tend to offset one another (Card, 1999; Ashenfelter, Harmon, \& Oosterbeek, 2000). While the coefficient on wages in table 8 is high relative to developed-country estimates of the returns to schooling, Krueger and Lindahl (2001) suggest that the returns to education are higher in poor countries.

${ }^{15}$ The average length of abduction is used in place of an ATE in column 2.
} 
Table 8.-The Correlates of Wages and the Decomposition of the Wage ATE

\begin{tabular}{|c|c|c|c|c|}
\hline Independent variable & $\begin{array}{c}(1) \\
\log (\text { Wage })^{a}\end{array}$ & $\begin{array}{c}(2) \\
\text { ATE (Table 3) }\end{array}$ & $\begin{array}{c}(3) \\
(1) \times(2)\end{array}$ & $\begin{array}{c}(4) \\
\% \text { of Wage ATE }\end{array}$ \\
\hline Years of education attained & $0.16[0.02]^{* * *}$ & -0.75 & -0.12 & $-55 \%$ \\
\hline Years experience $^{\mathrm{b}}$ & $0.05[0.01]^{* * *}$ & -0.74 & -0.03 & $-15 \%$ \\
\hline Index of social support & $0.04[0.03]$ & -0.16 & -0.01 & $-3 \%$ \\
\hline Indicator for serious injury & $-0.26[0.20]$ & 0.10 & -0.03 & $-12 \%$ \\
\hline Index of psychological distress & $-0.03[0.02]$ & 0.57 & -0.02 & $-8 \%$ \\
\hline Observations & 448 & & & \\
\hline$R^{2}$ & 0.142 & & & \\
\hline
\end{tabular}

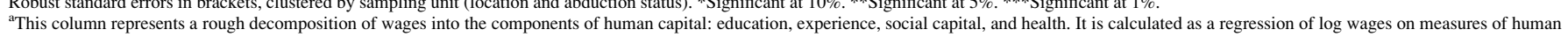
capital, weighted by inverse sample and attrition probabilities. The constant term is omitted from table,

$\mathrm{b}$ Experience is calculated as age - years of education -6 . Since there is no defined ATE for experience, the figure used represents the average abduction length (8.9 months, or 0.74 years).
.

Given the association between abduction length and education and between education and wages, we would expect a strong inverse relationship between abduction length and log wages. No such relationship appears to exist, however. The point estimate on abduction length is positive, close to 0 , and not significant. It is the violence-experienced coefficient that is negative and significant: each violent act is associated with an 8 percentage point decrease in wages. Length of abduction is unassociated with skilled employment.

The absence of a relationship between wages and abduction length (and the positive correlation with violence experienced) is inconsistent with the human capital mechanism we hypothesize above. The relationship between wages and violence does not appear to be driven by injuries; controlling for an injury indicator or an indicator for being in the top quartile of distress (regressions not shown). One possibility is that the log wage-violence correlation is spurious; the same regression using wage levels (rather than log wages) yields the expected negative coefficient on years abducted, although it is not statistically significant. The coefficient on violence experienced remains positive and is no longer significant. Our measure of wages, average gross daily earnings, is measured with error, the distribution is skewed, and values are missing for nonworkers. Moreover, the regressions in table 8 are vulnerable to endogeneity. Even so, given the relationship between education and both abduction length and wages, we would expect a large and statistically significant relationship between abduction length and wages. This failure to observe a relationship between abduction length and wages is puzzling, and suggests that a reduction in education and experience may not be the only causal channel by which abduction affects labor market outcomes. The result presents a puzzle and bears future investigation.

\section{Conclusion}

New data and a tragic natural experiment provide some of the first estimates of the nature, magnitude, and distribution of the effects of civil war on youth. The results suggest two main impacts of armed group participation operating by two channels: a human capital loss due to time away from schooling and work experience and higher levels of psychological distress concentrated in those who experience the most violence.

We can juxtapose these findings against current policy in Uganda, where funding has been focused on broad-based programs for the psychosocial reintegration of former child soldiers. With distress and aggression concentrated, more targeted and specialized psychosocial services are probably needed for those who have experienced the most violence (abducted or not). The most broad-based impact of abduction, meanwhile, appears to be economic and educational, implying that increased attention ought to be paid to education and economic programming. Evidence on the effectiveness of different programs is needed to make firm policy conclusions, however.

We interpret our findings as the incremental effect of conscription in communities already subjected to the horrors of war and abduction, an important quantity of interest if we wish to target aid and development assistance to the people who need them most. We would also like to measure the impacts of war itself, but we have neither the data nor the research design to do so. It remains a crucial area for future research. In the meantime, it is worth noting that the incremental impact of military service may be more important than the gap between war- and nonwar-affected populations, at least in Uganda. National survey data suggest that while the impact of the war on wealth may have been large, the educational impact has been small: nonabducted youth in the war zone have levels of education and literacy that are similar to or even greater than that in other parts of Uganda. We discuss these comparisons in the appendix. While selection undoubtedly biases any results, they do suggest that the gap between nonabducted youth in Acholiland and youth outside the region is not enormous. We do not have data to compare economic indicators, however, which we would assume to be significantly lower than the rest of Uganda.

Can we generalize these results? The psychosocial findings concur with academic literature on refugee mental health and an NGO literature on child protection. Both emphasize the resilience to violent trauma among youth (as described in section I). Combat may be no different. In the economic realm, the parallels to the conscription of American soldiers are striking. For instance, Angrist (1990) finds that white U.S conscripts from the Vietnam War experience 
a $15 \%$ decrease in long-term earnings, largely due to losses in relevant work experience.

While the Ugandan results are most easily generalized to other instances of forcible recruitment, we speculate that our results likely understate the consequences of voluntary participation in unpopular armed groups such as those in Sierra Leone, Liberia, and the Congo. Volunteer fighters in an unpopular war might see a greater loss in social capital and greater impact on mental health. Ugandan abductees have granted amnesty for any of their actions as soldiers and have been largely welcomed home with open arms, a remarkable community response that could mute the economic and psychosocial effects. Globally a third of child soldiers are thought to be forcibly recruited (ILO, 2003). For the other two-thirds, who might experience more social exclusion on return, the treatment effects estimated in this paper might be regarded as a minimum impact.

Finally, the time-away channel, if true, suggests that the Ugandan findings may be relevant for understanding other forms of child labor and interruptions of human capital accumulation more generally. Meng and Gregory (2007) find a sizable reduction in educational attainment (though little decrease in long-term earnings) among Chinese taken out of school during the Cultural Revolution. Causal estimates of the impact of agricultural child labor on education and earnings in both Vietnam and Tanzania suggest that a doubling of hours employed reduces school enrollment by nearly a third and educational attainment by 6\% (Beegle, Dehejia, \& Gatti, 2004, 2006). In the longer term, however, they find that this work experience can augment the child's wages and employment. These examples highlight the importance of the quality of the experience acquired by youth in place of formal education. Child labor or an event like the Cultural Revolution can offer the ability to acquire useful human and physical capital, muting the long-term economic impact. Child soldiering thus deserves to be singled out as one of the worst forms of child labor, not simply because of the obvious risk of injury and the terrible experiences of violence, but also because of the dramatic decrease in lifetime earnings ability that comes from the lack of transferable skills gained from the experience and consequent deficiency in human capital.

Ultimately, however, external validity is difficult to assess because of the paucity of microlevel data in areas of armed conflict. This suggests a need for more research in more zones of conflict. For this research to be accurate and comparable, greater attention ought to be paid to representative samples, accounting for attrition, and the careful identification of comparison groups. The aim should be to move from ad hoc to evidence-based policy in postconflict reintegration, redevelopment, and peacebuilding.

\section{REFERENCES}

Ajdukovic, Marina, and Dean Ajdukovic, "Impact of Displacement on the Psychological Well-Being of Refugee Children," International Review of Psychiatry 10:3 (1998), 186-195.
Allen, Tim, War and Justice in Northern Uganda: An Assessment of the International Criminal Court's Intervention (London: Crisis States Research Centre, Development Studies Institute, London School of Economics, 2005).

American Psychiatric Association, Diagnostic and Statistical Manual of Mental Disorders, 4th ed. (Washington, DC: American Psychiatric Association, 2000).

Angrist, Joshua D., "Lifetime Earnings and the Vietnam Era Draft Lottery: Evidence from Social Security Administrative Records," American Economic Review 80:3 (1990), 313-336.

"Estimating the Labor Market Impact of Voluntary Military Service Using Social Security Data on Military Applicants," Econometrica 66:2 (1998), 249-288.

Angrist, Joshua D., and Guido W. Imbens, "Two-Stage Least Squares Estimation of Average Causal Effects in Models with Variable Treatment Intensity," Journal of the American Statistical Association 90 (1995), 431-442.

Angrist, Joshua D., and Alan B. Krueger, "Why Do World War II Veterans Earn More Than Nonveterans?" Journal of Labor Economics 12:1 (1994), 74-97.

Annan, Jeannie, and Christopher Blattman, "The Mental Health of Young Soldiers: Mitigating the Impact of Abduction and Violence," Yale University working paper (2009).

Annan, Jeannie, Christopher Blattman, and Roger Horton, The State of Youth and Youth Protection in Northern Uganda: Findings from the Survey of War Affected Youth (New York: UNICEF, 2006).

Annan, Jeannie, Moriah Brier, and Filder Aryemo, "From 'Rebel' to 'Returnee': Daily Life and Reintegration for Youth in Northern Uganda," Yale University working paper (2008).

“Armies of Children," New York Times, October 12, 2006.

Ashenfelter, Orley, Colm Harmon, and Hessel Oosterbeek, "A Review of Estimates of the Schooling/Earnings Relationship, with Tests for Publication Bias," Labor Economics 6:4 (2000), 453-470.

Baird, Sarah, Joan Hamory, and Edward Miguel, "Tracking, Attrition, and Data Quality in the Kenyan Life Panel Survey, Round 1," University of California, Berkeley, Center for International and Development Economics Research, working paper (2008).

Barrera, Manuel, Irwin N. Sandler, and Thomas B. Ramsay, "Preliminary Development of a Scale of Social Support: Studies on College Students," American Journal of Community Psychology 9:4 (1981), 435-447.

BBC, "Child Soldiers Are a Time Bomb," BBC News (2007).

Beber, Bernd, and Christopher Blattman, "The Industrial Organization of Rebellion: The Logic of Forced Labor and Child Soldiering," Yale University working paper (2008).

Beck, Aaron, Robert A. Steer, and Margery G. Garbin, "Psychometric Properties of the Beck Depression Inventory: Twenty-Five Years of Evaluation," Clinical Psychology Review 8:1 (1988), 77-100.

Beegle, Kathleen, Rajeev H. Dehejia, and Roberta Gatti, "Why Should We Care About Child Labor? The Education, Labor Market, and Health Consequences of Child Labor," NBER working paper no. 10980 (2004).

"Child Labor, Crop Shocks, and Credit Constraints," Journal of Development Economics 81 (2006), 80-96.

Behrend, Heike, Alice Lakwena and the Holy Spirits: War in Northern Uganda, 1985-97 (London: James Currey, 1999).

Blattman, Christopher, "From Violence to Voting: War and Political Participation in Uganda," American Political Science Review 103:2 (2009), 231-247.

Blattman, Christopher, and Edward Miguel, "Civil War," Journal of Economic Literature 48:1 (2010), 3-57.

Boothby, Neil, Jennifer Crawford, and Jason Halperin, "Mozambique Child Soldier Life Outcome Study: Lessons Learned in Rehabilitation and Reintegration Efforts," Global Public Health 1:1 (2006), 87-107.

Branch, Adam, "Neither Peace nor Justice: Political Violence and the Peasantry in Northern Uganda, 1986-1998," African Studies Quarterly 8:2 (2005), 1-31.

Card, David, "The Causal Effect of Education on Earnings" (pp. 18011863), in O. Ashenfelter and D. Card (Eds.), Handbook of Labor Economics (Amsterdam, Elsevier, 1999).

Cohn, Ilene, and Guy S. Goodwin-Gill, Child Soldiers: The Role of Children in Armed Conflict (Oxford: Clarendon Press, 1994).

Collier, Paul, "On the Economic Consequences of Civil War," Oxford Economic Papers 51 (1999), 168-183. 
Costa, Dora L., and Matthew E. Kahn, "Health, Wartime Stress, and Unit Cohesion: Evidence from Union Army Veterans," Demography 47:1 (2010), 46-66.

CSUCS, Child Soldiers Global Report 2004 (London: Coalition to Stop the Use of Child Soldiers, 2005).

Derluyn, Ilse, Eric Broekaert, Gilberte Schuyten, and Els De Temmerman, "Post-Traumatic Stress in Former Ugandan Child Soldiers," Lancet 363:9412 (2004), 861.

Doom, Ruddy, and Koen Vlassenroot, "Kony's Message: A New Koine? The Lord's Resistance Army in Northern Uganda," African Affairs 98:390 (1999), 5-36.

Dyregrov, Atle, Rolf Gjestad, and Magne Raundalen, "Children Exposed to Warfare: A Longitudinal Study," Journal of Traumatic Stress 15:1 (2002), 59.

Dyregrov, Atle, Leila Gupta, Rolf Gjestad, and Eugenie Mukanoheli, "Trauma Exposure and Psychological Reactions to Genocide among Rwandan Children," Journal of Traumatic Stress 13:1 (2000), 3-21.

Fabrigar, Leandre R., Duane T. Wegener, Robert C. MacCallum, and Erin J. Strahan, "Evaluating the Use of Exploratory Factor Analysis in Psychological Research," Psychological Methods 4:3 (1999), 272 299.

Falaris, Evangelos M., "The Effect of Survey Attrition in Longitudinal Surveys: Evidence from Peru, Cote d'Ivoire and Vietnam," Journal of Development Economics 70:1 (2003), 133-157.

Fitzgerald, John, Peter Gottschalk, and Robert Moffitt, "An Analysis of Sample Attrition in Panel Data: The Michigan Panel Study of Income Dynamics," Journal of Human Resources 33:2 (1998), 251-299.

Ghobarah, Hazem A., Paul Huth, \& Bruce Russett, "Civil Wars Kill and Maim People-Long after the Shooting Stops," American Political Science Review 97:2 (2003), 189-202.

Hearst, Norman, Thomas B. Newman, and Stephen B. Hulley, "Delayed Effects of the Military Draft on Mortality: A Randomized Natural Experiment," New England Journal of Medicine 314:10 (1986), 620-624.

Heckman, James J., "Sample Selection Bias as a Specification Error," Econometrica 47:1 (1979), 153-162.

Hirano, Keisuke, Guido W. Imbens, and Geert Ridder, "Efficient Estimation of Average Treatment Effects Using the Estimated Propensity Score," Econometrica 71:4 (2003), 1161-1189.

Hollifield, Michael, Teddy D. Warner, Nityamo Lian, Barry Krakow, Janis H. Jenkins, James Kesler, Jayne Stevenson, and Joseph Westermeyer, "Measuring Trauma and Health Status in Refugees: A Critical Review," JAMA 288:5 (2002), 611-621.

Honwana, Alcinda, Child Soldiers in Africa (Philadelphia: University of Pennsylvania Press, 2005)

Humphreys, Macartan, and Jeremy M. Weinstein, "What the Fighters Say: A Survey of Ex-Combatants in Sierra Leone, June-August 2003," CGSD working paper (2004).

"Handling and Manhandling Civilians in Civil War: Determinants of the Strategies of Warring Factions," American Political Science Review 100:3 (2006), 429-447.

"Demobilization and Reintegration," Journal of Conflict Resolution 51:4 (2007), 531-567.

"Who Fights? The Determinants of Participation in Civil War," American Journal of Political Science 52:2 (2008), 436455.

ILO, Wounded Childhood: The Use of Child Soldiers in Armed Conflict in Central Africa (Washington, DC: International Labor Organization, 2003)

Imbens, Guido W., "Sensitivity to Exogeneity Assumptions in Program Evaluation" American Economic Review 93:2 (2003), 126-132.

Imbens, Guido W., and Wilbert van der Klaauw, "Evaluating the Cost of Conscription in the Netherlands," Journal of Business and Economic Statistics 13:2 (1995), 207-215.

Imbens, Guido W., and Jeffrey Wooldridge, "Recent Developments in the Econometrics of Program Evaluation," NBER working paper no. 14251 (2008)

Kinzie, J. David, William H. Sack, Richard H. Angell, Spero Manson, and Ben Rath, "The Psychiatric Effects of Massive Trauma on Cambodian Children: I. The Children," Journal of the American Academy of Child and Adolescent Psychiatry 25:3 (1986), 370376.
Krueger, Alan B., and Mikael Lindahl, "Education for Growth: Why and for Whom?" Journal of Economic Literature 39:4 (2001), 11011136.

Lee, David S., "Training, Wages, and Sample Selection: Estimating Sharp Bounds on Treatment Effects," NBER working paper no. 11721 (2005)

Machel, Graca, Impact of Armed Conflict on Children (New York: UNICEF, 1996).

MacMullin, Colin, and Marianne Loughry, An Investigation into the Psychosocial Adjustment of Formerly Abducted Child Soldiers in Northern Uganda (Kampala: International Rescue Committee, 2002).

Marshall, Monty G., and Ted R. Gurr, Peace and Conflict 2005: A Global Survey of Armed Conflicts, Self-Determination Movements, and Democracy (College Park: Center for International Development and Conflict Management, University of Maryland, 2005).

Meng, Xin, and Robert Gregory, "Exploring the Impact of Interrupted Education on Earnings: The Educational Cost of the Chinese Cultural Revolution," IZA discussion paper no. 2548 (2007).

Miller, Kenneth E., and Lisa M. Rasco, The Mental Health of Refugees: Ecological Approaches to Healing and Adaptation (Mahwah, NJ: Erlbaum, 2004).

Mincer, Jacob, Education, Experience, and Earnings (New York: Columbia University Press, 1974).

Mollica, R. F., C. Poole, L. Son, C. C. Murray, and S. Tor, "Effects of War Trauma on Cambodian Refugee Adolescents' Functional Health and Mental Health Status," Journal of the American Academy of Child and Adolescent Psychiatry 36:8 (1997), 1098-1106.

Omara-Otunnu, Amii, Politics and the Military in Uganda, 1890-1985 (London: Macmillan in association with St. Antony's College, Oxford, 1994)

Pham, Phuong, Patrick Vinck, and Eric Stover, Abducted: The Lord's Resistance Army and Forced Conscription in Northern Uganda (Berkeley: Human Rights Center, University of California, Berkeley, and New Orleans: Payson Center for International Development, Tulane University, 2007).

Rosenbaum, Paul R., and Donald B. Rubin, “Assessing Sensitivity to an Unobserved Binary Covariate in an Observational Study with Binary Outcome," Journal of the Royal Statistical Society, B, 45:2 (1983), 212-18

Rubin, Donald B., "Estimating Causal Effects of Treatments in Randomized and Nonrandomized Studies," Journal of Educational Psychology 66:5 (1974), 688-701.

Sack, William, Richard Angell, J. David Kinzie, and Ben Rath, "The Psychiatric Effects of Massive Trauma on Cambodian Children: II. The Family, the Home and the School," Journal of the American Academy of Child Psychiatry 25:3 (1986), 377-383.

Shepler, Susan A., Conflicted Childhoods: Fighting over Child Soldier in Sierra Leone (Berkeley: University of California Press, 2005).

Strauss, John, and Duncan Thomas, "Health, Nutrition, and Economic Development," Journal of Economic Literature 36:2 (1998), 766817.

Thomas, Duncan, Elizabeth Frankenberg, and James P. Smith, "Lost But Not Forgotten: Attrition and Follow-up in the Indonesia Family Life Survey," Journal of Human Resources 36:3 (2001), 556-592.

Wessells, Mike, Child Soldiers: From Violence to Protection (Cambridge, MA: Harvard University Press, 2006)

\section{APPENDIX}

\section{The Impact of War on Nonabducted Youth}

The treatment effects estimated in table 3 identified the incremental impact of conscription on already war-affected youth. The impact of war on nonabducted youth is not known, but could be estimated if we possessed a comparable sample of youth outside the war zone. Unfortunately, a valid counterfactual is not available. We can turn, however, to national survey data for a very rough assessment of the impact of war. The 2002/ 03 Uganda National Household Survey (Collier, 1999; Ghobarah, Huth, \& Russett, 2003) collected data on more than 8,000 youth, excluding the war-affected (Acholi) districts. Three education measures (years of schooling, enrollment, and illiteracy) and three household asset indicators (cell phone, bicycle, and radio ownership) were measured by both the 
Table A1.-Education and Wealth Differences between Nonabducted Acholi and Other Ugandan Youth

\begin{tabular}{|c|c|c|c|c|c|c|}
\hline & (1) & (2) & (3) & (4) & (5) & (6) \\
\hline & \multicolumn{3}{|c|}{ Education Meaures } & \multicolumn{3}{|c|}{ Asset Ownership Indicator } \\
\hline & $\begin{array}{l}\text { Years of } \\
\text { Education }\end{array}$ & $\begin{array}{c}\text { Indicator for } \\
\text { School Enrollment }\end{array}$ & $\begin{array}{l}\text { Illiteracy } \\
\text { Indicator }\end{array}$ & Cell Phone & Bicycle & Radio \\
\hline $\begin{array}{l}\text { Nonabducted sample mean } \\
\text { (Acholi region) } \\
\text { Age-adjusted mean in } \\
\text { non-Acholi regions } \\
\text { (from } 2002 / 03 \text { UNHS) } \\
\text { relative to Acholi } \\
\text { nonabducted sample mean: }\end{array}$ & 7.6 & 0.56 & 0.09 & 0.16 & 0.41 & 0.38 \\
\hline Non-Acholi north & $-0.15[0.13]$ & $-0.01[0.01]$ & $0.13[0.03]^{* * *}$ & $-0.03[0.01]^{* *}$ & $0.02[0.02]$ & $0.13[0.01]^{* * *}$ \\
\hline Central region & $-0.45[0.13]^{* * *}$ & $-0.17[0.01]^{* * *}$ & $0.10[0.02]^{* * *}$ & $0.03[0.02]^{* *}$ & $0.07[0.02]^{* * *}$ & $0.30[0.01]^{* * *}$ \\
\hline Eastern region & $0.28[0.12]^{* *}$ & $-0.01[0.01]$ & $0.14[0.02]^{* * *}$ & $0.02[0.01]$ & $0.01[0.02]$ & $0.23[0.01]^{* * *}$ \\
\hline Western region & $-0.45[0.12]^{* * * *}$ & $-0.12[0.01]^{* * *}$ & $0.09[0.02]^{* * *}$ & $0.00[0.01]$ & $0.00[0.02]$ & $0.26[0.01]^{* * *}$ \\
\hline Observations & 8830 & 8839 & 5445 & 8840 & 8842 & 8842 \\
\hline$R^{2}$ & 0.12 & 0.45 & 0.03 & 0.01 & 0.02 & 0.17 \\
\hline
\end{tabular}

Acholi region. The mean differences come from a regression of the dependent variable on regional dummies and dummies for age at the time of survey.

national survey and the survey conducted by the authors (see Annan et al., 2006).

Age-adjusted mean differences between nonabducted youth in the Acholi region (from the author's data set) and youth in four other Uganda regions (other northern districts, as well as Uganda's central, eastern, and western regions) suggest that economically, Acholi youth are substantially behind their Ugandan peers but educationally remain roughly on par. Table A1 displays the mean of each education and asset measure for nonabducted Acholi youth in the survey sample, as well as the results of a regression of the measure on indicators for each region and age. The coefficients on each region thus indicate the age-adjusted mean difference between Acholi youth and non-Acholi youth. We see that educational attainment among the Acholi sample appears to be higher than in the central and western regions comparable to the other northern districts, and less than in eastern region (column 1). School enrollment is higher and illiteracy is lower in the Acholi sample than in all other regions, however (columns 2 and 3). The results may be driven by difficulties and biases in cross-regional and cross-data-set comparison. They also do not account for school quality differences, which may be large. They are nevertheless consistent with the explanation that with war's diminishment of economic opportunities, youth in Acholiland may have elected to remain longer in school. At the very least, the war does not appear to have set Acholi youth far behind their Ugandan peers.

In terms of wealth, the data suggest that Acholi youth have access to fewer assets. Cell phone and bicycle ownership are mildly lower in the Acholi sample (columns 4 and 5), and radio access is dramatically lower (column 6). Unfortunately, national earnings data for youth are not available. 